\title{
Perspectives on Women's Higher Education Leadership from Around the World
}

\author{
Karen A. Longman \\ Department of Higher Education, Azusa Pacific University, 701 East Foothill Blvd., Azusa, CA 91702, USA; \\ klongman@apu.edu; Tel.: +1-626-387-5706
}

Received: 5 July 2018; Accepted: 5 July 2018; Published: 19 July 2018

Numerous studies in recent years have tracked dimensions related to the status of women both within specific countries and from an international perspective. For example, the Millennium Development Goals (MDGs) in eight specific areas that were established by the United Nations for the period from 2000-2015 included targets for improving gender equality and the empowerment of women, including improved access to education (United Nations New Millennial Goals 2017). The UN subsequently established 17 Sustainable Development Goals for the period of 2016-2030, one of which focuses on providing "women and girls with equal access to education, health care, decent work, and representation in political and economic decision-making process"(United Nations Sustainable Development Goals 2017). Similarly, the World Economic Forum's Global Gender Gap Report (World Economic Forum 2017), which draws data annually from 177 countries, serves as "a framework for capturing the magnitude of gender-based disparities and tracking their progress over time" (p. vii). Data are organized into four subindexes for analysis: Economic Participation and Opportunity, Educational Attainment, Health and Survival, and Political Empowerment. Over the past decade, the Nordic countries have ranked highest in terms of a minimal gender gap in these areas, with Iceland, Norway, and Finland achieving the most favorable ratings.

For example, a review of the status of women leaders within politics and the business sectors around the world by Goryunova et al. (2017) documented that only $22.7 \%$ of parliament positions and $9 \%$ of CEO positions were held by women. Within the US context, the non-profit organization Catalyst has annually tracked the percentage of women within the S\&P 500 corporations-a combination of 500 large companies that have common stock in one of the American stock market indexes; Catalyst's most recent report found that women made up only $5.0 \%$ of CEOs, $21.2 \%$ of Board seats, $26.5 \%$ of Executive/Senior-Level Officials and Managers, 36.9\% of First/Mid-Level Officials and Managers, and $44.7 \%$ of total employees (Catalyst 2018).

This underrepresentation of women in leadership has detrimental ripple effects across communities and countries. In fact, scholars have repeatedly documented the benefits of having diverse perspectives around the leadership table (Catalyst 2013; Page 2007; Woolley et al. 2010). In addition, numerous others have emphasized the importance of having women's voices present in decision-making (Eagly 2015; Kezar 2014; Sandberg 2013; Madsen et al. 2015) as part of bringing that desired diversity.

Notably, recent research in various countries seems to indicate movement toward greater support for women in leadership, which may relate to the growing dissatisfaction not only with economic conditions but also with the attitudes and behaviors of those holding government offices. Survey research involving 64,000 participants in 13 countries that was conducted by Gerzema and D'Antonio (2013) identified widespread dissatisfaction regarding the male-normed models of those currently in power. In response to a survey item worded: "I'm dissatisfied with the conduct of men in my country" (p. 6), a majority of all three subgroups of respondents indicated agreement (global average of adults $=57 \%$; men $=54 \%$; and millennials $=59 \%$ ). In summarizing key findings from their survey data, the researchers concluded: 
Universally, it seemed that people had grown frustrated by a world dominated by codes of what they saw as traditionally masculine thinking and behavior: codes of control, competition, aggression, and black-and-white thinking that have contributed to many of the problems we face today, from wars and income inequality to reckless risk-taking and scandal. (p. 7)

At this particular time in world history, it is interesting to note that scholars have emphasized the importance of having greater diversity in leadership, and specifically for greater representation by women in leadership. Similar to the importance of increasing the rates of educational access and school completion by girls as reflected in the UN's New Millennium Goals (2000-2015) and the follow-up U. N. Sustainable Development Goals (2016-2030), access by women to higher education-and having role models by women in higher education leadership — has ripple effect benefits, given that postsecondary institutions shape the lives of future generations.

This special issue focuses on the topic of "Perspectives on Women's Higher Education leadership from Around the World," offering research and narratives of women in academic leadership from the United States, the United Kingdom, Australia, India, China, and Saudi Arabia. The opening article, "How Organizational Culture Shapes Women's Leadership Experiences (Longman et al. 2018)," presents the findings of a grounded theory study involving 16 participants working in faith-based institutions regarding the role of "organizational culture" and "organizational fit" in their leadership aspirations and experiences. Given that certain theological traditions within Christianity have historically limited the role of women in leadership, the study resulted in the identification of four subgroups of participants ranging from those who did not perceive that gender issues in the culture influenced their work or roles within the institution to participants who offered explicit criticism regarding the gendered dynamics evident in the culture in their institutions and in Christian higher education more broadly. The resulting theory and model reflected that various influences represented either a "push" (i.e., diminishing aspirations or willingness to move into or remain in leadership) or a "pull" (i.e., increasing the desire to become or remain a leader in that context) and had implications for anyone considering leadership opportunities vis-à-vis the realities of the organization's culture.

The second article, "Ascending: An Exploration of Women's Leadership Advancement in the Role of Board of Trustee Chair," (Scott 2018) presents the findings of a phenomenological study involving five women who had held of role of chair of the board of trustees of a private institution in a Southeast state in the U.S. Given that the board of trustees has the responsibility of hiring the president, who then is responsible for hiring senior-level leaders, the role of board chair is significant in shaping the future direction of these private institutions. The researcher conducted an in-person interview (with the opportunity for a second follow-up interview) with each participant to explore the experiences of these women board chairs, along with any perceived barriers or obstacles they reported encountering in their leadership role. In describing what had contributed to achieving the role of the board chair, certain skills or "skill sets" were identified, such as the ability to organize and lead an effective meeting, being held in high esteem by their peers, and having served in a variety of other leadership positions that provided knowledge related to effective board leadership.

Turning to the role of women's leadership development programming as an important strategy for preparing and equipping greater numbers of future women leaders in higher education, autoethnographic reflections about one institution's model program are presented in an article titled "Rethinking Women's Leadership Development: Voices from the Trenches." (Selzer et al. 2017). The program, which operates through the provost's office, was designed to identify and prepare mid-career faculty and staff women for senior-level leadership roles. Components of the curriculum include leadership skills such as visioning and strategic alignment, finance and operations, and understanding and building culture. Three former participants based their self-reflection of this seven-month program on the leader identity work of Ely et al. (2011), which emphasizes the importance of three related components: “(1) considering topics in light of gender bias; (2) supporting women's identity work; and (3) focusing on leadership purpose." In addition to the benefits gained through 
the use of the self-reflective process that was used in the collaborative autoethnography, the authors reported two key findings: "(1) to effectively develop women leaders, work must be done at the personal, interpersonal, and organizational levels, as these levels are interrelated and interdependent; and (2) women's multiple identities must be engaged." This article offers a full-orbed overview of the literature related to women and leadership and a helpful analysis of specific components of one institution's leadership development programming; it can also serve as an example of the benefits of collaborative autoethnography as a research methodology.

Another autoethnographic research project, this time from the UK context, is found in the article titled "The Implications of Contractual Terms of Employment for Women and Leadership: An Autoethnographic Study in UK Higher Education" (Vicary and Jones 2017). It offers a touching first-person perspective-yet a perspective that is well-grounded in related theory and research-on the experiences of individuals who lack the permanency and status of full-time employment within a university setting. The author notes that employment under a short-term or non-permanent contract has become common practice in higher education; such contracts are often referred to as "sessional" or "zero-hours" (meaning that no specific hours of work are guaranteed) and typically are renewed each term or each year. This autoethnographic study is grounded in the recognition that more than half (54\%) of all academic staff and $49 \%$ of teaching staff in UK universities are employed under this type of non-permanent contract, $48 \%$ of whom are women. With courage and transparency, the author reveals how the lack of permanent and respected employment within academe can contribute to professional isolation, lowered self-esteem, and can dampen leadership aspirations due to lack of career progression opportunities.

Also written from the context of the United Kingdom, yet on a topic relevant to the higher education scenario of many other countries, is the article titled "Increasing Gender Diversity in Senior Roles in HE: Who Is Afraid of Positive Action?" (Manfredi 2017). Here, the author directly addresses the controversial topic of whether postsecondary institutions should adhere to "positive action" (referred to as "affirmative action" in other cultural contexts) as a constructive means of addressing the underrepresentation of certain groups (including women) in senior-level leadership roles. Referencing the UK context in specific, the author draws attention to section 159 of the UK Equality Act 2010, whereby employers are allowed to give preference to an applicant from an underrepresented group in tie-breaking situations. Yet the fairness of that approach has been challenged for a variety of reasons, including perceptions of reverse discrimination and tokenism. Citing both UK and European aspirational targets for advancing more women into senior-level leadership roles of postsecondary institutions, the author provides five compelling arguments for adhering to the practice of positive action in the recruitment and promotion of individuals from underrepresented groups.

Drawing data from two studies that focused on women in leadership (one based in the United Kingdom; the other from Australia), the article entitled "Fixing the Women or Fixing the Universities" (Burkinshaw and White 2017) addresses the gendered power relations at play in universities that often hold women back, despite efforts implemented to support their advancement. Using different methodologies—one study involved qualitative interviews with 18 senior women (e.g., vice chancellors); the other drew data from a quantitative survey-this project emerged from the experiences of two women representing different generations, both of whom had been negatively impacted in terms of their leadership aspirations by increasing job insecurity and continuous organizational restructuring that affected gender power relations at work. The precariousness for women having a career involving academic leadership was explored through the lenses of previous studies that have identified women as "the problem" rather than recognizing how organizational culture often contributes to the barriers faced by women in university settings.

Another interesting study from the context of higher education in Australia that takes a constructive tone is represented by the article titled "Frank and Fearless: Supporting Academic Career Progression for Women in an Australian Program" (Parker et al. 2018). When a 2009 analysis of data at a large Australian university identified that gender parity at the level of lecturer and 
senior lecturer did not translate to gender parity at more senior levels, a targeted program (a "Career Progression for Women" course) was developed to support the advancement of more women from senior lecturer to associate professor rank. Because applicants for this promotion were expected to demonstrate leadership abilities in the domains of teaching, research, engagement, and/or clinical service, various aspects of leadership development were central to the program's design. This article contains helpful descriptive material and an evaluation of various aspects of the course (e.g., guest speakers, development of a portfolio, the women-only structure) that could prove beneficial to other campuses seeking to initiate related supportive programming.

Three additional articles add rich international perspectives to this special issue of Administrative Sciences. The first, titled "Towards Social Justice in Institutions of Higher Learning: Addressing Gender Inequality in Science \& Technology through Capability Approach" (Kameshwara and Shukla 2017), analyzes qualitative data from 40 interviews with faculty and staff at a university in South India to identify socio-cultural barriers faced by women studying in the fields of science and technology. Among the 30 respondents who were women, self-reported concerns were expressed regarding the "hard attitude" they had experienced, particularly within the male-dominated disciplines (i.e., science and technology). Historically and culturally, the authors report a private-public divide in India that has been associated with notions of gender; women's work has been viewed within the private domain of household, whereas men's work has been associated with authority and productivity. Also contributing to the underrepresentation of women in science and technology have been limitations on resources such as funding and educational opportunities, despite efforts by the government to address these concerns. While recognizing that discrimination and marginalization are present, the authors call for a capability approach to be advanced in addressing the status quo; in other words, women must be equipped with the identified capabilities (e.g., self-esteem, motivation levels, administrative and decision-making posts) that can be instrumental in tackling gender disparity and inequality in the Indian higher education context.

Similarly, revisiting the earlier themes of how organizational culture and/or socio-cultural influences shape the leadership aspirations and experiences of women in various settings, the perspective of Chinese academics is represented in the article entitled "Women and Leadership in Higher Education in China: Discourse and the Discursive Construction of Identity" (Zhao and Jones 2017). Noting that only $4.5 \%$ of the higher education senior-level leadership roles in that country have been held by women, the authors present the findings of qualitative interviews with nine women from two Chinese universities to examine "how women construct multiple identities, the interplay of identities, and the influence of broader societal Discourses of gender and leadership."

The findings revealed the extent to which the participants viewed the interplay of various identities (e.g., mothers, teachers, managers) in ways that were consistent with Confucian thought and societal norms (e.g., being supportive of the husband, tending to household chores, fulfilling duties); notably, all nine participants distanced themselves from leadership as a professional identity.

The concluding article in this special issue, titled "An Overview of the Current State of Women's Leadership in Higher Education in Saudi Arabia and a Proposal for Future Research Directions" (Alsubaie and Jones 2017), turns the reader's attention to an area of the world where relatively little is known about women's leadership. Similar to several other articles that preceded it, these authors address the concern expressed by Eagly (2015) that much of the literature related to leadership has been written from a Western orientation, reflecting assumptions that are inaccurate for other cultural contexts. The authors note that despite stereotypical images of Saudi women and culture, the status of women in the Kingdom of Saudi Arabia has been modified and improved in social, political, and economic life over the past two decades. Describing the methodology that led to this article as a "desk-based study," the work of these authors represents a helpful contribution to the literature both by synthesizing the available literature on women and leadership in higher education in Saudi Arabia and in proposing specific directions that future related research might take. 
In conclusion, the full participation of women in leadership of postsecondary institutions is critical both for wise decision-making and for numerous other financial, organizational culture, and relational reasons, as articulated by Madsen in a synthesis of the literature titled: "Why Do We Need More Women in Leadership of Higher Education?" (Madsen 2015). Interestingly, a key finding of the international research project of Gerzema and D'Antonio that involved 64,000 participants was the significant level of agreement by adult respondents $(66 \%)$ and by male respondents $(65 \%)$ with the statement: "The world would be a better place if men thought more like women" (Gerzema and D'Antonio 2013, p. 8). While working toward that goal, increasing the visibility and engagement of women in higher education leadership also merits urgent focused attention and energy.

\section{References}

Alsubaie, Azzah, and Karen Jones. 2017. An Overview of the Current State of Women's Leadership in Higher Education in Saudi Arabia and a Proposal for Future Research Directions. Administrative Sciences 7: 36. [CrossRef]

Burkinshaw, Paula, and Kate White. 2017. Fixing the Women or Fixing Universities: Women in HE Leadership. Administrative Sciences 7: 30. [CrossRef]

Catalyst. 2013. Why Diversity Matters. Available online: http://www.catalyst.org/system/files/why_diversity_ matters_catalyst_0.pdf (accessed on 5 July 2018).

Catalyst. 2018. Pyramid: Women in S\&P 500 Companies. June 1. Available online: http:/ /www.catalyst.org/ knowledge/women-sp-500-companies (accessed on 5 July 2018).

Eagly, Alice H. 2015. Foreword. In Women and Leadership around the World. Edited by Faith Wambura Ngunjiri, Karen A. Longman and Cynthia Cherrey. Charlotte: Information Age Publishing, pp. ix-xiii.

Ely, Robin J., Herminia Ibarra, and Deborah M. Kolb. 2011. Taking gender into account: Theory and design for women's leadership development programs. Academy of Management Learning \& Education 10: 474-93.

Gerzema, John, and Michael D'Antonio. 2013. The Athena Doctrine: How Women (and the Men Who Think Like Them) Will Rule the Future. San Francisco: Jossey-Bass.

Goryunova, Elizabeth, Robbyn T. Scribner, and Susan R. Madsen. 2017. The current status of women leaders worldwide. In Handbook of Research on Gender and Leadership. Edited by Susan R. Madsen. Northampton: Edward Elgar Publishing, pp. 3-23.

Kameshwara, Kalyan Kumar, and Tanu Shukla. 2017. Towards Social Justice in Institutions of Higher Learning: Addressing Gender Inequality in Science \& Technology through Capability Approach. Administrative Sciences 7: 22.

Kezar, Adrianna. 2014. Women's contributions to higher education leadership and the road ahead. In Women and Leadership in Higher Education. Edited by Karen A. Longman and Susan R. Madsen. Charlotte: Information Age Publishing, pp. 117-34.

Longman, Karen, Jessica Daniels, Debbie Lamm Bray, and Wendy Liddell. 2018. How Organizational Culture Shapes Women's Leadership Experiences. Administrative Sciences 8: 8. [CrossRef]

Madsen, Susan R. 2015. Why do we need more women leaders in higher education? HERS Research Brief, No. 1. Available online: http:/ /hersnet.org/wp-content/uploads/2015/07/HERS-Research-Brief-No.-1-SusanMadsen-.pdf (accessed on 5 July 2018).

Madsen, Susan R., Faith Wambura Ngunjiri, Karen A. Longman, and Cynthia Cherrey, eds. 2015. Women and Leadership around the World. Charlotte: Information Age Publishing.

Manfredi, Simonetta. 2017. Increasing Gender Diversity in Senior Roles in HE: Who Is Afraid of Positive Action? Administrative Sciences 7: 19. [CrossRef]

Page, Scott E. 2007. The Difference: How the Power of Diversity Creates Better Groups, Firms, Schools, and Societies. Princeton: Princeton University Press.

Parker, Polly, Belinda Hewitt, Jennifer Witheriff, and Amy Cooper. 2018. Frank and Fearless: Supporting Academic Career Progression for Women in an Australian Program. Administrative Sciences 8: 5. [CrossRef]

Sandberg, Sheryl. 2013. Lean in: Women, Work, and the Will to Lead. New York: Alfred A. Knoph.

Scott, Heather Inez Ricks. 2018. Ascending: An Exploration of Women's Leadership Advancement in the Role of Board of Trustee Chair. Administrative Sciences 8: 7. [CrossRef] 
Selzer, Robin, Amy Howton, and Felicia Wallace. 2017. Rethinking Women's Leadership Development: Voices from the Trenches. Administrative Sciences 7: 18. [CrossRef]

United Nations New Millennial Goals. 2017. Available online: http:/ /www.un.org/millenniumgoals/ (accessed on 5 July 2018).

United Nations Sustainable Development Goals. 2017. Available online: https://www.un.org/ sustainabledevelopment/gender-equality/ (accessed on 5 July 2018).

Vicary, Anne, and Karen Jones. 2017. The Implications of Contractual Terms of Employment for Women and Leadership: An Autoethnographic Study in UK Higher Education. Administrative Sciences 7: 20. [CrossRef]

Woolley, Anita Williams, Christopher F. Chabris, Alex Pentland, Nada Hashmi, and Thomas W. Malone. 2010. Evidence for a collective intelligence factor in the performance of human groups. Science 330: 686-87. [CrossRef] [PubMed]

World Economic Forum. 2017. The Global Gender Gap Report. Available online: http:/ /www3.weforum.org/ docs/WEF_GGGR_2017.pdf (accessed on 5 July 2018).

Zhao, Jiayi, and Karen Jones. 2017. Women and Leadership in Higher Education in China: Discourse and the Discursive Construction of Identity. Administrative Sciences 7: 21. [CrossRef]

(C) 2018 by the author. Licensee MDPI, Basel, Switzerland. This article is an open access article distributed under the terms and conditions of the Creative Commons Attribution (CC BY) license (http:/ / creativecommons.org/licenses/by/4.0/). 